\title{
Comentario al libro Valores $y$ virtudes en medicina
}

\section{Book review: Values and virtues in medicine}

Este nuevo libro: Valores y Virtudes en Medicina está coordinado por tres médicos y un filósofo, que también figuran entre sus 24 autores. Consta de tres

Partes: 1) Aspectos Teóricos; 2) Dignidad Humana y 3) Estudios Empíricos. Sin embargo, esto no revela la muy amplia variedad de su contenido: mi primera reacción al consultar los títulos de algunos capítulos fue de sorpresa, pues encontré uno llamado: "Cine y enseñanza de los valores humanos", otro con el título de "M, el Vampiro de Düsseldorf y la dignidad humana".

La lectura del texto pronto me demostró que el libro entero gira alrededor de un solo tema: el análisis crítico de la práctica actual de la medicina tomando en cuenta la participación de las dos tendencias conocidas como la medicina basada en la evidencia y la medicina basada en valores.

La primera parte, Aspectos Teóricos, consta de 7 capítulos, de los que deseo destacar 3 que me parecieron particularmente claros y convincentes en sus planteamientos. El primero es el número 3, "Conocimiento Tácito en la Práctica Médica", que se refiere a las habilidades, experiencias, reflejos y destrezas que el médico necesita, posee y requiere para su práctica, pero que no están en los libros; o sea que no son conocimientos enunciables en proposiciones, lo que se conoce como conocimiento científico. Este otro tipo de cono- cimiento, el tácito, forma una parte fundamental del oficio y no sólo se refiere a acciones físicas, sean de exploración o quirúrgicas, sino también mentales, y con frecuencia contribuyen en forma fundamental y definitiva al buen manejo de los pacientes. Cuando yo era estudiante de medicina nos referíamos a este conocimiento tácito con el término genérico de "ojo clínico", e indefectiblemente se lo adjudicábamos a aquellos pocos (muy pocos) de nuestros profesores que con una mirada y un par de preguntas al paciente ya habían hecho el diagnóstico. Para ellos toda la tardada rutina de la primera consulta, con el interrogatorio llevado sistemáticamente con un orden clásico, la exploración física completa, el estudio de los exámenes de laboratorio y gabinete que ya estuviesen hechos, que los estudiantes debíamos hacer al enfrentar un paciente nuevo era, como señalan los autores de este capítulo, como "andar en bicicleta". Los profesores mencionados podían detectar automáticamente los elementos claves, sintetizando en forma automática y con frecuencia espontánea (es decir, sin pensarlo en el momento sino más bien a posteriori) los datos claves para el diagnóstico. Alguna vez le pregunté a uno de mis maestros (el Dr. Jorge Flores Espinoza) cuál era el secreto de su infalible puntería y me contestó sonriendo: "Son los años, doctorcito..."

El Capítulo 6 de esta Primera Parte se refiere a la “Responsabilidad Médica en México. Aspectos 
Legales." y es excelente. Yo formé parte de la CONAMED durante 4 años y suscribo todas las observaciones y comentarios que hacen los autores de este importante texto, que incluye los textos pertinentes de la legislación mexicana actualizada, así como una breve, pero útil bibliografía.

El Capítulo 7, titulado "Virtudes en medicina", empieza citando a Aristóteles, a San Agustín y a Santo Tomás de Aquino; lo que me asustó un poco, pero con la lectura se me fue quitando el miedo. Los autores examinan la inteligencia, la ciencia y la sabiduría, la veracidad, la justicia y el valor, y los ejemplifican con 4 casos clínicos muy interesantes y muy comunes.

En la última parte, escriben de otras virtudes como la humildad, la compasión, la reverencia, la justicia, la prudencia, la promesa de confianza, la simplicidad y la fortaleza. Su último párrafo dice:

"Así como los casos presentados, cada día se presentan distintos dilemas éticos y son los médicos quienes deciden el rumbo del mismo. Por lo tanto, es imperativo reflexionar sobre nuestras acciones y decisiones, porque sus implicaciones trascienden más allá de toda normatividad, porque afectan al "otro", a "uno mismo" y a la "sociedad". Como fácilmente se expanden los vicios, el médico debe esforzarse en expandir en cadena las virtudes, siendo él mismo quien enseñe estas virtudes con su propio ejemplo."

Amén.

Los 3 capítulos siguientes (del 9 al 11), se refieren a la dignidad humana. Todos estamos de acuerdo en que ésta es sumamente importante, aunque precisar su contenido no resulta fácil. Se trata de un concepto particularmente vago, con un sentido casi individual o personal, o por lo menos estar sujeto, en diferentes grupos sociales, a variaciones mucho más amplias que las ideas de libertad, de justicia y de otros derechos humanos.

La principal característica de la dignidad es su heterogeneidad. Lo que yo considero como esencial de mi dignidad como ser humano, seguramente que no coincide con la de un campesino tibetano, un estudiante de filosofía argentino, un miembro de los Marines de Estados Unidos o un policía de tránsito en el DF. Lo individual de la dignidad humana puede ejemplificarse con el ejemplo muy mexicano de la "mordida", término "vernáculo" para la acción del policía que solicita dinero para no levantar una infracción al conductor de un automóvil que se pasó un alto. Este policía es menos digno que el chofer que rehúsa la oferta de "arreglarse", pero el punto no es quién tiene la razón, sino la heterogeneidad del concepto de dignidad. Este comentario obedece a que en los tres capítulos mencionados conté 11 maneras diferentes de concebir o de definir a la dignidad. Naturalmente que la dignidad humana debe respetarse, pero este respeto no es a una propiedad específica o característica legal y/o universal del sujeto, sino a sus derechos humanos, a su autonomía y a su libertad y también a su historia, a sus creencias y a su ambiente familiar y social. Cuando las circunstancias permiten que el ser humano actúe con pleno ejercicio de sus derechos y con completa libertad, de acuerdo con sus creencias y sus tradiciones, sus usos y costumbres, y sin interferir con los derechos y la libertad de acción y pensamiento de los demás, puede decirse que también se está respetando su dignidad, aunque en mi concepto ya se estará agregando muy poco.

La $3^{\text {a }}$ parte del libro "Valores y Virtudes de la Medicina" es la más heterogénea, porque describe la estructura y funciones de un grupo transfuncional de ética clínica; los problemas de la práctica clínica en México; los dilemas creados por los cuidados paliativos y por las variaciones culturales de los pacientes y termina con un esquema 
de los Servicios de Salud deseables para México. Los datos presentados son muy valiosos y revelan tanto la preocupación como el compromiso de los autores con la situación que prevalece en la práctica de la medicina en nuestro país.

Quiero terminar mis comentarios sobre este libro con un resumen de mi posición frente a un punto directamente relacionado con su contenido: la naturaleza de la ética propiamente médica, basada en los objetivos de la profesión, en contraste con la ética del médico, que incluye muchos otros aspectos históricos, morales, sociales, económicos, políticos y de otras disciplinas.

Yo concibo a la ética médica propiamente dicha, o sea a la ética específica de la profesión, como limitada a los principios y las acciones relacionados directamente con los objetivos de la medicina, que pueden resumirse en los siguientes tres:

1. Preservar la salud.

2. Curar, y cuando no se puede curar, aliviar, y siempre consolar y acompañar al enfermo y a sus familiares.

3. Evitar las muertes prematuras e innecesarias.

Todavía es posible expresar estos tres objetivos en forma más concreta, como: "Lograr que los seres humanos vivan jóvenes y sanos toda su vida y finalmente mueran sin sufrimientos y con dignidad, lo más tarde que sea posible."

En mi opinión, debe distinguirse entre la ética médica y la ética del médico, porque tienen objetivos y contenidos distintos, aunque al final convergen en su función de proporcionar la atención a la salud de la más alta calidad. En realidad, este planteamiento es casi el mismo que se presenta en este libro, Valores y Virtudes en Medicina, en el que se promueve el ejercicio de la profesión por medio de las acciones com- binadas de la medicina basada en la evidencia y la medicina basada en los valores. Para mi, la ética médica basada en los objetivos de la medicina, se resume en las 4 reglas siguientes del comportamiento de los médicos:

1. Estudio continuo de la medicina. El médico tiene la obligación moral de mantenerse al día en sus conocimientos científicos y técnicos, con objeto de ofrecerle a sus pacientes lo mejor que tiene la profesión para su diagnóstico y tratamiento. Esto se logra conservando la práctica del estudio continuo, de la asistencia a cursos y congresos, de la integración a sociedades científicas y del interés permanente en la actualización de la información pertinente. El médico que deja de ser un estudiante de su profesión no sólo es un médico malo y un mal médico, también es un médico inmoral.

2. Información y docencia médica. La palabra "doctor" se deriva de la voz latina doscere, que significa enseñar. No sólo en castellano sino en varios otros idiomas, las palabras "médico" y "doctor" se usan como sinónimos. Desde sus orígenes, el médico tiene la obligación moral de instruir a sus enfermos, a sus familiares y a todos los que puedan beneficiarse con ello, en la naturaleza, evolución, manejo y pronóstico de su enfermedad. Esta norma ética se aplica también a sus colegas, al resto del personal de salud, a sus alumnos (si los tiene) y a todos los que puedan beneficiarse con sus conocimientos. El médico que no enseña no sólo es un médico malo y un mal médico, también es un médico inmoral.

3. Investigación científica biomédica. El médico tiene la obligación moral de contribuir (o de intentar hacerlo) a 
aumentar los conocimientos que le permiten atender mejor a sus pacientes y mejorar el contenido de sus instrucciones y enseñanzas. No se trata de convertirse en un investigador de tiempo completo, pero sí de realizar su práctica médica con los ojos abiertos a los problemas sin solución conocida, a pensar en ellos y a tratar de contribuir a resolverlos, dentro de sus conocimientos y capacidades. El médico que no investiga no sólo es un médico malo y un mal médico, también es un médico inmoral.

4. Manejo integral del paciente. El médico tiene la obligación moral de atender no sólo la enfermedad, sino todo el padecimiento de su paciente. El enfermo busca la consulta no porque tiene fiebre, dolor, debilidad y otros síntomas, según su enfermedad, sino también porque está asustado, angustiado, no quiere dejar de trabajar, se preocupa por su familia, tiene miedo de que lo operen y también de morirse. Eso es lo que el enfermo padece y lo que necesita es que lo alivien de su padecimiento, no sólo de su enfermedad. El médico que no se involucra en el manejo integral de sus pacientes no sólo es un médico malo y un mal médico, también es un médico inmoral.

En este resumen de las reglas del comportamiento ético del médico confluyen la medicina basada en la evidencia y la medicina basada en valores. Pero quiero terminar planteando una preocupación que tengo sobre la especificidad de algunos de los valores mencionados en este libro, en especial los promovidos como "principios de ética médica" por Beauchamp y Childress a partir de 1979 y que han ido creciendo en popularidad en los últimos años.
Estos autores (ninguno de los dos es médico; uno es profesor de filosofía y el otro de teología) ofrecen su conocida lista de 6 "principios de ética médica":

1. Autonomía

2. No hacer daño

3. Hacer el bien

4. Justicia

5. Veracidad

6. Confidencialidad

Desde luego que la observación de estos principios contribuye en forma muy positiva a que la relación médico-paciente se de en forma óptima, con lo que se facilita el alcance de los objetivos de la medicina, por lo que debe recomendarse su cumplimiento. Pero no son ni específicos ni característicos de la medicina, sino que más bien son principios que deben observarse en todo tipo de relación interhumana. Como la relación médico-paciente es una de las formas más cercanas y más íntimas de las relaciones interhumanas debe cuidarse que los principios señalados se cumplan, pero esto ocurre también en muchas otras formas de relación interhumana, como cuando se consulta a un notario para hacer un testamento, o se hace un contrato con un arquitecto para construir una casa, o hasta cuando un estudiante se acerca a un profesor para que le dirija su tesis. En todos estos casos (y muchos otros más) los principios de "ética médica" de Beauchamp y Childress tienen relevancia, de modo que si se cumple con ellos, las relaciones interhumanas serán mejores. Pero dudo que podamos aceptarlos como principios de "ética médica".

Dr. Ruy Pérez Tamayo Universidad Nacional Autónoma de México 